\title{
CONCEPÇÕES DE PROFESSORES SOBRE O CONHECIMENTO MATEMÁTICO: UM OLHAR DA FILOSOFIA DA EDUCAÇÃO MATEMÁTICA
}

\author{
Marlisa Bernardi de Almeida ${ }^{1}$
}

\begin{abstract}
RESUMO: Esta pesquisa relata brevemente um estudo realizado acerca dos entendimentos dos professores de Matemática do Ensino Fundamental sobre a formação profissional tendo como base teórica a Filosofia da Educação Matemática. A pesquisa foi realizada com os professores de três escolas públicas estaduais do Paraná, da região da Cantuquiriguaçu. O trabalho teve como objetivo principal analisar as concepções dos professores em relação ao processo de ensino e aprendizagem da Matemática, tentando enquadrar estas concepções dentro das três grandes correntes filosóficas do conhecimento matemático: logicismo, formalismo e intuicionismo. Os dados para o desenvolvimento deste trabalho foram obtidos através de questionário com questões abertas. As respostas permitiram apontar a presença marcante da concepção formalista da Matemática, como também do logicismo, podendo ser possível perceber, raramente nas respostas, alguns indícios do intuicionismo. Através da análise das respostas foi possível observar que as três concepções filosóficas do conhecimento matemático formam o ecletismo das concepções dos professores, deixando evidente que possuem ainda a forte influência do cartesianismo.
\end{abstract}

Palavras-chave: Filosofia da matemática; Concepções de ensino; Formação de professores.

\section{TEACHER CONCEPTIONS ON MATHEMATICAL KNOWLEDGE: A LOOK AT THE PHILOSOPHY OF MATHEMATICAL EDUCATION.}

\begin{abstract}
This research briefly reports a study about the understandings of Mathematics teachers of Elementary School on professional training having as theoretical basis the Philosophy of Mathematics Education. The research was carried out with the teachers of three state public schools of Paraná, of the region of Cantuquiriguaçu. The main objective of this work was to analyze teachers' conceptions regarding the teaching and learning process of Mathematics, trying to frame these conceptions within the three great philosophical currents of mathematical knowledge: logicism, formalism and intuitionism. The data for the development of this work were obtained through a questionnaire with open questions. The answers allowed to point out the marked presence of the formalist conception of Mathematics, as well as of logicism,
\end{abstract}

\footnotetext{
${ }^{1}$ Mestre em Educação Matemática. Especialista em Metodologia da Matemática e Psicopedagogia. Licenciada em Matemática e Pedagogia. Professora de Matemática e Pedagoga na Rede Estadual do Paraná. Colégio Estadual Laranjeiras do Sul. Contato: marlisabernardi@ yahoo.com.br 
and it may be possible to perceive, rarely in the answers, some indications of intuitionism. Through the analysis of the answers it was possible to observe that the three philosophical conceptions of mathematical knowledge form the eclecticism of the teachers' conceptions, making it clear that they still have the strong influence of Cartesianism.

Keywords: Philosophy of mathematics; conceptions of teaching; teacher training.

\section{FILOSOFIA DA MATEMÁTICA E FILOSOFIA DA EDUCAÇÃO MATEMÁTICA}

A Filosofia da Matemática é compreendida atualmente, segundo Bicudo (1999), como um campo de conhecimento e de investigação que lança seu olhar sobre a Matemática buscando

[...] entender seu significado no mundo, no mundo da ciência, o sentido que faz para o homem, de uma perspectiva antropológica e psicológica, a lógica da construção de seu conhecimento, os modos de expressão pelos quais aparece ou materializa-se, cultural e historicamente, a realidade dos seus objetos, a gênese do seu conhecimento" (BICUDO, 1999, p. 26).

Segundo esta autora (1999) as perguntas da Filosofia da Matemática focalizam especificamente a Matemática e seus objetos. Tais perguntas, derivadas da Filosofia (O que existe? - O que é o conhecimento? - O que vale?), são exploradas na Filosofia da Matemática na seguinte perspectiva:

- Qual é a "realidade" dos objetos matemáticos?

- Como são conhecidos os objetos matemáticos e quais os critérios que sustentam a veracidade das afirmações matemáticas?

- Os objetos e as leis matemáticas são inventados (construídos) ou descobertos?

A Filosofia da Educação da Matemática, de acordo com Bicudo (1999) traz da Filosofia as características do pensamento analítico, sistemático e universal, sendo que da Filosofia da Educação,

[...] toma as análises e reflexões sobre educação, ensino, 
aprendizagem, escolarização, avaliação, políticas públicas da educação, os procedimentos assumidos para trabalhar esses temas, para mencionar alguns, e os olha da perspectiva daquele que está preocupado com a educação do outro e, em particular, com o significado que a matemática, por meio do seu ensino e da aprendizagem, assume (BICUDO, 1999, p. 30).

A partir disso, constitui-se como um campo autônomo que se ocupa com um pensamento abrangente sobre os temas envolvidos no campo da Educação Matemática. A Filosofia da Educação Matemática tem por objetivo conhecer, criticar, delinear e buscar a identidade da Educação Matemática (BICUDO, 1999). Nesse entorno podemos relacionar algumas de suas questões fundamentais.

- O que é a Matemática como disciplina escolar e fenômeno cultural social?

- Como objetos ontológicos e metodológicos, tais como certeza, verdade e prova, da filosofia da matemática podem ser tornar objetos pedagógicos?

- Como se vê a matemática como fenômeno lingüístico?

As questões referentes tanto a Filosofia da Matemática como a Filosofia da Matemática importantes de analisar e de se estudar, pois compartilhamos a ideia de Bicudo (1999), sendo que:

[...] não há prática ou teoria pedagógica que não seja, de modo consciente ou não, influenciada, quando não determinada, por uma concepção filosófica sobre a natureza da matemática. $\mathrm{O}$ educador precisa necessariamente responder às questões filosóficas fundamentais sobre o estatuto do objeto matemático, sobre a natureza da verdade matemática, sobre o caráter do método matemático, sobre a finalidade da matemática, sobre o estatuto do conhecimento matemático (BICUDO, 1999, p. 57).

\section{AS CONCEPÇÕES FILOSÓFICAS E O ENSINO DA MATEMÁTICA}

A dimensão filosófica do conhecimento matemático, de acordo com Machado (1994) comporta três categorias de estudiosos a respeito do conhecimento matemático:

- Os racionalistas (ênfase na razão);

- Os empiristas (ênfase na experiência);

- Kant (que buscou o equilíbrio entre razão e experiência). 
No grupo dos racionalistas, aqueles que primam pelo aspecto lógico do conhecimento matemático, destacam-se:

* Platão (427-347 a.C.), defendendo que a Matemática trata apenas de objetos que estão no mundo das ideias, sendo assim ela existia a priori no indivíduo.

* Descartes (1596-1650), que refutou a experiência como fonte de conhecimento. A Matemática é vista como estritamente racional e lógica. A intuição e a dedução são únicas fontes de conhecimento e são operações de nosso entendimento. Ela é compreendida como a raiz de todas as ciências.

* Leibniz (1646-1716), para quem a certeza do conhecimento está baseada unicamente na razão.

É importante entender a visão platônica, pois ela está presente em muitas concepções de ensino e também oculta nos currículos escolares. Esta concepção remete a um ensino de Matemática centrado na razão, ou seja, que a criança aprenderia repetindo exercícios padrões dados e explicados pelo professor, até compreender os raciocínios envolvidos e ser capaz de reproduzi-los.

A crença de que a Matemática é importante porque desenvolve o raciocínio se fundamenta na concepção filosófica de Platão e a ideia de que a Matemática é instrumento para outras ciências vêm da concepção filosófica cartesiana.

No grupo dos empiristas, estão aqueles que acreditam na preponderância do aspecto empírico na constituição do conhecimento matemático, dentre eles podemos citar:

Aristóteles (384 a.C a 322 a. C), para o qual os conhecimentos matemáticos poderiam ser comprovados com experiências do mundo real. Vale destacar que Aristóteles não é propriamente um empirista, sendo que as ideias de abstração vêm com este estudioso. O conhecimento para Aristóteles, apesar de ter sua origem na experiência, afasta-se cada vez mais dela.

Newton (1643-1727), que defendia que os conhecimentos matemáticos eram deduzidos a partir da experiência e podiam ser verificados por ela.

Locke (1632-1704), o qual rejeitou a Matemática como um conhecimento lógico. O conhecimento matemático para ele seria fundamentado na intuição e obtido mediante a experiência. 
$>\quad$ Hume (1711-1776), que defendia que somente a experiência podia dar segurança à ciência.

Essa concepção empirista encontra-se presente também hoje nos discursos de educadores que defendem que a Matemática está presente no cotidiano e tem aplicações na vida prática.

Percebe-se assim nestas duas concepções a separação entre razão e experiência, somente com Kant, ocorre o equilíbrio entre a razão e a experiência. Para ele o conhecimento não era só do sujeito e nem somente do objeto, mas da interação entre ambos. Sendo assim, o conhecimento matemático seria obtido mediante a dedução (raciocínio, razão) - a priori; mas poderiam ser comprovados mediante a experiência sintético. Kant distingue o conhecimento a priori do conhecimento a posteriori. $\mathrm{O}$ conhecimento a priori é o conhecimento que se fundamenta na razão e é independente da experiência. Pelo contrário, o conhecimento a posteriori, ou empírico, consiste em proposições fundamentadas na experiência, isto é, nas observações do mundo físico. Por sua vez, o conhecimento analítico é o conhecimento explicativo. Afirmar que por exemplo que "um segmento de reta é a distância mais curta entre dois pontos", constitui, para Kant, um exemplo de conhecimento sintético a priori.

Dessa forma o conhecimento matemático não seria analítico nem sintético, mas entraria numa terceira classe: sintéticos a priori. Com isso deduz-se que: o conhecimento matemático é obtido no mundo das ideias, mas pode ser aplicado e comprovado no mundo real.

Através dessa concepção kantiana é que o professor pode compreender que a Matemática apesar de ter sua origem no mundo real, ela é constituída essencialmente de abstrações e generalizações.

Analisando a influência das dimensões filosóficas do conhecimento matemático na prática pedagógica dos professores, consideramos que o viés da filosofia perpassa a discussão transversalmente, na tentativa de entender a Matemática crítica e reflexivamente, percebendo a constituição desta ciência.

A intencionalidade desta perspectiva de abordagem é considerar além da Matemática, a Educação Matemática, ou seja, as relações que estão entrelaçadas no ensinar e aprender. Acreditamos, embasados nas discussões apresentadas por estes autores que há a necessidade de questionarmos as questões levantadas acima, para que 
os professores façam opções teóricas, metodológicas, didáticas de forma mais consciente, possibilitando processos reflexivos de sua prática.

O conhecimento em Filosofia da Educação Matemática e suas reflexões são determinantes na prática pedagógica do educador, por esclarecer, ao professor, as diversas concepções de matemática, de ensino e de educação e, conseqüentemente, determinará os saberes e a aceitação da disciplina por parte dos educandos (BICUDO, 1999).

Porém, a literatura indica o estado nada alentador e aponta a prática docente dos professores reprodutivistas como responsável. As questões até aqui mencionadas conduziram-nos a formulação do seguinte questionamento: Que concepções de ensino de matemática transitam no cotidiano escolar? Quais as determinações que levam os professores terem este entendimento? Levando em consideração esses questionamentos, analisamos as concepções dos professores em relação à organização do processo ensino aprendizagem, extraindo indicadores dos condicionantes sociais, históricos, políticos que contribuíram para a determinação da ação docente.

O pressuposto norteador do presente estudo é: ao instituir objetivo ou atividade teórica/prática em que a finalidade seja o ensino da matemática, o professor precisa responder as questões filosóficas não só sobre a natureza e o desígnio da ciência que fundamenta a disciplina que leciona como também da educação.

\section{METODOLOGIA}

A metodologia de pesquisa adotada foi pesquisa de campo, através de um estudo exploratório de cunho qualitativo.

Participaram do estudo, doze docentes da Rede Pública do Estado do Paraná, do município de Laranjeiras do Sul, localizado na região da Cantuquiriguaçu que atuam na disciplina de Matemática nas séries finais do Ensino Fundamental. Os instrumentos utilizados para a coleta de dados foram questionários abertos e entrevistas aplicadas aos professores. Para proceder à análise qualitativa das informações obtidas, utilizou-se a Técnica de Análise de Conteúdo proposta por Bardin (1979).

A Análise de Conteúdo de Bardin (1979) é um conjunto de técnicas de análise de comunicação que utiliza procedimentos sistemáticos e objetivos de descrição do 
conteúdo das mensagens, a qual permitiu confrontar metodologicamente a verificação e interpretação dos significados das mensagens (manifestos ou subjacentes) atribuídos à avaliação da aprendizagem pelos participantes da pesquisa. Na discussão dos resultados, procurou-se comparar as informações obtidas sob o ponto de vista dos professores e alunos com os dados disponíveis na literatura especializada em filosofia da educação matemática.

\section{DISCUSSÃO DOS RESULTADOS}

Através da análise de conteúdo baseada em Bardin (1979), observamos que para os professores pesquisados a aprendizagem não é processo, mas produto que se dá imediatamente após “explicação de um conteúdo". A concepção comportamentalista skineriana de aprendizagem predomina no ideário dos professores, ou seja: cada estímulo deve gerar prontamente uma resposta.

Escolhemos algumas respostas, as quais foram as que mais se repetiram ao longo das análises realizadas, as quais ilustram claramente que a concepção formalista da Matemática está ainda muito presente no cotidiano escolar.

P1: "Eu tento, mas não sei mais o que fazer. Procuro atividades diferenciadas, mas não sei se é isto o certo. Fico confusa com tantas teorias, só sei que quero ver meu aluno aprendendo."

P2: "Na minha opinião um bom professor de Matemática deve fazer seus alunos gostarem da matéria que será ensinada para que assim aprendam com facilidade. Por isso, através de minhas aulas eu procuro fazer com que meus alunos gostem da Matemática, procuro explicar bem o conte trazer atividades interessantes e estar atento as dúvidas deles."

P4: "Em minhas aulas eu utilizo bastantes exercícios: exercícios do livro didático do aluno, exercícios que tragam mais desafios ao pensamento dos alunos, pois acredito que é através da resolução de exercícios e problemas que desenvolvemos o pensamento matemático de nossos alunos."

P9: "Eu aprendi a trabalhar com a exposição interrogada: ou seja, explicar a matéria questionando o aluno, fazendo ele pensar sobre. Mas não há como fugir dos exercícios de fixação e das atividades de revisão antes da prova."

P6: "Eu sei que é necessário fazer com que os alunos participem mais das aulas de matemática, expondo seu pensamento, o jeito que 
fizeram, discutam com seus colegas diversas estratégias para o mesmo resultado, mas acontece que da forma como está organizado nosso sistema escolar, eu ainda não consigo fazer nada disso que leio nas revistas de educação matemática. Por isso procuro fazer como eu posso e aquilo que é possível dentro da realidade de nosso sistema escolar. Eu utilizo exercícios e atividades diversas, procurando que na medida do possível o aluno resolva expondo como fez, interrogo porque fez daquela maneira, mas o tempo não permite que eu faça isso em todas as aulas. Mas sempre faço a correção coletiva no quadro explicando para todos. E faço também a comum e usadíssima revisão de conteúdo antes das provas."

As respostas dos professores são reveladoras de uma formação profissional marcada pela extrema linearidade positivista incutida a muito em nossa sociedade, impulsionada pela visão cartesiana desde o século XVI.

A presença marcante das concepções idealistas positivistas revela que os professores têm ainda a crença de que a matemática é aprendida através de exercícios, de repetição, de explicação e não por via da construção do conhecimento.

Há professores que até procuram modificar sua prática pedagógica embasados no entendimento de um referencial teórico. Porém, a efetivação do desejo de mudança acaba tropeçando na falta de tempo para uma reflexão sistemática e também pela própria organização do sistema escolar vigente no estado. Sendo que o que acontece no cotidiano escolar acaba tornando o professor de Matemática um mero repassador de conteúdos impedindo-o de participar do exercício da pesquisa.

Esse contexto é propiciador para que os esforços dos professores para promover o abandono à pedagogia fundamentada no formalismo clássico da atemática, seja descartado facilmente, pois encontram muitos empecilhos.

Assim, as posturas e valores, próprios da filosofia positivista dominante na prática pedagógica, são reproduzidos, fortalecidos e legitimados. Dessa forma, o planejamento de inúmeras atividades com o intuito de melhoria da aprendizagem matemática dos alunos, cai numa mesma rotina: explicação, exemplos, exercícios (muitos) e correção.

Mas se o professor tiver consciência das concepções filosóficas que as fundamentam e suas implicações, isto poderá começar a ser modificado.

Entretanto, não basta querer se inserir numa concepção pedagógica, sem acreditar, apostar, defender e, sobretudo, lutar por ela. Verificamos, então, que a impregnação de uma formação linear, não permitiu que os professores, mesmo com 
muito esforço, traçassem um caminho pedagogicamente articulado, que permitisse aos poucos, se libertarem de um "método" ou de uma forma de ver a ciência cartesiana imposta para a sociedade desde o século XVII.

Portanto, é fácil anunciar a presença marcante da concepção formalista da matemática que, com algumas poucas doses do intuicionismo, formam o ecletismo das atividades pedagógicas realizadas no cotidiano das aulas de Matemática.

Ressalta-se que por meio deste trabalho, estamos analisando os fatos, apontando quais são as concepções de ensino predominante e trazendo evidências de um perfil da formação profissional e humana da qual também nos inserimos.

Os professores de matemática apontam as suas dificuldades no enfrentamento das questões que não satisfazem seus ideais a respeito da relação com seus alunos e a consequiente aprendizagem. Eles têm consciência de que há algo errado e até buscam alternativas de apresentação de conteúdos para os estudantes. Percebemos a preocupação deles com a real aprendizagem dos alunos.

No entanto, as respostas revelam também que questões internas da matemática e do processo pedagógico são despercebidas pelos professores. Para estes, a matemática é um todo inquestionável. Nesse contexto produzido, historicamente, gerou-se professores com convicções acirradas e, contraditoriamente, criadora de ingenuidade teórica que os levam a viver pedagogicamente sempre em estado de angústia e de impotência.

Assim sendo, a maneira de pensar filosoficamente impondo questões fundamentais como: Por que se ensina matemática? O que se espera deste ensino? Que benefícios ela fornece? Tais questionamento conduzem à realidade muito mais significativa do que o apenas transmitir o conteúdo e decorar fórmulas.

Conforme constam nas Diretrizes Curriculares do Estado do Paraná (DCEs) (2008), a Matemática é organizada por meio de signos e por isso ela torna-se uma linguagem e um instrumento importante para resolução e compreensão dos problemas e necessidades sociais dentro de cada contexto. Esses conhecimentos matemáticos são considerados instrumentos de compreensão e intervenção para a transformação da sociedade: nas relações de trabalho, na política, na economia, nas relações sociais e culturais. Além disso, esses conhecimentos dão suporte para outras ciências.

Por isso, ter certo domínio sobre a Matemática é uma questão de emancipação como meio de compreensão e intervenção na sociedade. Assim sendo, é impossível não 
ressaltar o valor educativo da Matemática como ferramenta indispensável para resolução de diversas situações do cotidiano, desde uma simples compra de supermercado até o mais complexo projeto de desenvolvimento econômico.

A Matemática é considerada um bem cultural e os conhecimentos matemáticos deveriam ser contemplados em todos os aspectos no contexto escolar. De acordo com Rodrigues (2005, p. 48) "pensar matematicamente tem sido apontado como essencial numa sociedade complexa que demanda diversas abordagens para soluções de problemas".

Serrazina (2002, p.10) afirma que:

Ser-se matematicamente competente na realização de uma dada tarefa implica, não só ter conhecimentos necessários, como a capacidade de os identificar e mobilizar na situação concreta, mas ainda a disposição para fazê-lo efetivamente.

Entretanto, conforme aponta Rodrigues (2005) geralmente a Matemática escolar continua a ser apresentada apenas em seu aspecto formal, e muitas vezes desprovida de significados, não conseguindo despertar nos alunos a estética de suas formulações e muito menos o espírito investigativo.

Segundo Serrazina (2003, p. 7),

a escola tem ainda que contribuir para alterar a imagem social da matemática: uma disciplina rotulada como difícil e a que só alguns, muito poucos, têm acesso, que está em oposição com a idéia de que a Matemática deve ser para todos e que todos podem aprender Matemática.

Segundo as DCE’s (2008) se faz necessário resgatar, para o processo de ensino e aprendizagem, a importância do conteúdo matemático e da disciplina Matemática.

Para tal é imprescindível que o estudante se aproprie do conhecimento de forma que "compreenda os conceitos e princípios matemáticos, raciocine claramente e comunique ideias matemáticas, reconheça suas aplicações e aborde problemas matemáticos com segurança" (LORENZATO, VILA, 1993, p. 41). 
Neste sentido "o trabalho docente necessita emergir da disciplina Matemática e ser organizado em torno do conteúdo matemático e, por conseguinte, se faz necessário uma fundamentação teórica e metodológica" (DCE's, p. 45).

A Educação Matemática entendida com base nestes pressupostos terá como meta a incorporação do conhecimento matemático, objetivando que o aluno seja capaz de superar o senso comum. Para isso deverá priorizar a criação de estratégias, a comprovação, a justificativa, o espírito crítico, a criatividade, a iniciativa pessoal, a persistência advinda do desenvolvimento da confiança na própria capacidade de conhecer e enfrentar desafios.

\section{CONSIDERAÇÕES FINAIS}

A disciplina de Matemática, portanto, prevê a formação de um estudante crítico, capaz de agir com autonomia nas suas relações sociais. Neste sentido, aprende-se Matemática não somente por sua beleza ou pela consistência de suas teorias, mas também para que, a partir dela, o homem amplie seu conhecimento e, por conseguinte, contribua para o desenvolvimento da sociedade.

A presente concepção está elucidada nas DCE's (2008), e de acordo com esta cabe ao professor de Matemática a sistematização dos conteúdos matemáticos que emergem das aplicações, superando uma perspectiva utilitarista, sem perder o caráter científico da disciplina e de seu conteúdo. Ir além do senso comum pressupõe conhecer a teoria científica, cujo papel é oferecer condições para apropriação dos aspectos que vão além daqueles observados pela aparência da realidade (DCE’s 2008).

É necessário que o processo pedagógico em Matemática contribua para que o estudante tenha condições de constatar regularidades, generalizações e apropriação de linguagem adequada para descrever e interpretar fenômenos matemáticos e de outras áreas do conhecimento.

Essa concepção, já defendida, no então Currículo Básico do Estado do Paraná, sustenta que: 
construir seus próprios instrumentos para resolver problemas, estar preparado para perceber estes mesmos problemas, desenvolver o raciocínio lógico, a capacidade de conceber, projetar e transcender o imediatamente sensível (PARANÁ, 1990, p. 66).

Observa-se que os professores acreditam na concepção apresentada nas DCE’s (2008), entretanto, faltam-lhes subsídios tanto teóricos quanto metodológicos para que de fato possam efetivá-la em sua prática pedagógica, visto que a formação inicial não proporcionou uma reflexão profunda do por que e para que ensinar Matemática, partindo de uma concepção filosófica mais abrangente.

Espera-se que este artigo venha a contribuir como mais um ponto de vista para os educadores, tentando instigar e propiciar uma reflexão sobre a sua prática pedagógica e as concepções filosóficas que nela estão presentes, as quais certamente influenciam todo o processo de ensino e aprendizagem.

\section{BIBLIOGRAFIA}

BARDIN, L. Análise de conteúdo. Lisboa: Edições 70, 1979.

BICUDO, M. A. V. Filosofia da educação matemática concepções e movimento. Brasília: Plano, 1999.

FIORENTINI, D. Alguns modos de ver e conceber o ensino da matemática no Brasil. Revista Zetetiké. Rio Grande do Sul, ano 3, nº 4, 1995.

LORENZATO. S.; VILA, M. C. Século XXI: qual matemática é recomendável? Revista Zetetiké. Campinas, ano 1, n. 1, p. 41 - 49. 1993.

MACHADO, N. J. Matemática e realidade: análise dos pressupostos filosóficos que fundamentam o ensino da matemática. São Paulo: Cortez, 1994.

MIGUEL, A. A constituição do formalismo pedagógico clássico em educação matemática. Revista Zetetiké. Campinas: UNICAMP/ CEPEM, ano 3, n 3, 1995.

PARANÁ. Secretaria do Estado da Educação. Departamento de Educação Básica. Diretrizes Curriculares de Matemática. Curitiba, 2008.

RODRIGUES, J. M. S. Formação matemática de professores de atuação multidisciplinar nas séries iniciais do ensino fundamental: indicativos com vista a estudos de noções de probabilidade. 2005. 242f. Dissertação (Mestrado em Educação). Pós-Graduação em Educação, Universidade Federal do Paraná - UFPR, Curitiba, 2005. 
SERRAZINA, L. A formação para o ensino de matemática: perspectivas futuras. Educação Matemática em Revista, São Paulo, SBEM, ano 10, n.14, ago 2003. 